\title{
Editorial
}

\section{Drug discovery for periodontitis}

Gingivitis or periodontitis (involving alveolar bone loss) is the major cause of tooth loss in adults [1]. It is most commonly associated with bacterial biofilm commonly known as plaque. The interactions between host defense mechanisms and plaque lead to plaque buildup. Poor dental hygiene, hormonal shifts in pregnancy, diabetes, human immunodeficiency virus, and some medication, such as phenytoin, calcium channel blockers, and cyclosporin, can further increase plaque buildup [2, 3]. Patients with periodontitis are at higher risks for cardiovascular diseases [4], low birth weight [5] among others [6].

Chronic periodontitis is the most common form of periodontitis, is plaque-induced and is a major cause of tooth loss [7]. Active bone loss can be triggered by changing oral bacteria flora. Porphyromonas gingivalis ( $P$. gingivalis) is one of the common oral bacteria flora.

In this issue, the report by Ashwin Kumar R et al. [8] described a technique targeting prolyl tripeptidyl peptidase from $P$. gingivalis with bioactive compounds from Rosmarinus officinalis. The in silico technique is a newer process of discovery of drug candidates in the fields of medicine, biotechnology, and pharmacology. The potential medicinal compound has to be optimized to increase the affinity, selectivity, efficacy, metabolic stability, and bioavailability before the clinical trial process of this investigational new drug. Later, the compound has to go through several phases of animal and human testing following a very specific path established by the regulatory agencies to ensure that the drugs are safe and effective when approved for widespread use in humans. Pharmacovigilance mechanisms have to be in place to look for rare side effects which may not become evident in clinical trials.
Therefore, the discovery of new drugs for public health use involves a healthy interaction between scientists, academia, patent laws, and regulatory agencies. Prevention should be the primary strategy that is potentially the most costeffective way to cope with this common disease. Some initial strategies should be adopted, such as oral hygiene, smoking cessation, and frequent oral examination, to identify the early lesion and early treatment.

\section{References}

[1] Williams RC. Periodontal disease. N Engl J Med. 1990; 322:373.

[2] Laudenbach JM, Simon Z. Common dental and periodontal diseases: evaluation and management. Med Clin North Am. 2014; 98:1239-60. Epub 2014 Oct 18.

[3] Steele RM, Schuna AA, Schreiber RT. Calcium antagonist-induced gingival hyperplasia. Ann Intern Med. 1994; 120:663-4.

[4] Beck JD, Offenbacher S. The association between periodontal diseases and cardiovascular diseases: a state-of-the-science review. Ann Periodontol. 2001; 6:9.

[5] Offenbacher S, Katz V, Fertik G, Collins J, Boyd D, Maynor G, et al. Periodontal infection as a possible risk factor for preterm low birth weight. J Periodontol. 1996; 67(10 Suppl):1103.

[6] Hayes C, Sparrow D, Cohen M, Vokonas PS, Garcia RI. The association between alveolar bone loss and pulmonary function: the VA dental longitudinal study. Ann Periodontol. 1998; 3:257.

[7] Burt B, Research, science and therapy committee of the American Academy of periodontology. Position paper: epidemiology of periodontal diseases. J Periodontol. 2005; 76:1406.

[8] Ramalingam AK, Selvi SGA, Jayaseelan VP. Targeting prolyl tripeptidyl peptidase from Porphyromonas gingivalis with bioactive compounds from Rosmarinus officinalis. Asian Biomed (Res Rev News). 2019; 13:197-203.

*Correspondence to: Editorial Office of Asian Biomedicine, Faculty of Medicine, Chulalongkorn University, Bangkok 10330, Thailand, e-mail: abmjournal@chula.ac.th 